\title{
The Effect of Upper Incisor Anteroposterior Position Changes on the Lip Profile in Class I Malocclusion
}

\author{
Okky Windyasari \\ Orthodontic Resident \\ Faculty of Dentistry, University of Sumatera Utara \\ Medan, Indonesia \\ windmile82@gmail.com
}

\author{
Muslim Yusuf \\ Lecturer of Orthodontic \\ Faculty of Dentistry, University of Sumatera Utara \\ Medan, Indonesia
}

\begin{abstract}
Soft tissue analysis has always been an integral part of the diagnosis and planning of orthodontic treatment. Treatment plans in Class I malocclusions, with or without the extraction of the first four premolars are still debated, since the perceived premolar extraction effect will be "flattening face". The Pterigomaxillary Vertical (PMV) reference line is used for evaluation of soft-tissue and hard-tissue position changes in this study. Cross-sectional research design of the cephalogram before and after treatment of forty subjects measured the linear change of incisor position and then evaluated its effect on lip position. There is a change in the position of the upper incisor over the lip position in the non-extraction treatment of Class I malocclusions and by the extraction of the first four premolar treatments, which also affect the nasolabial angle. In non-extraction Class I malocclusion treatment, $1 \mathrm{~mm}$ of incisor retractions will change the position of the lips posteriorly as far as $0.034 \mathrm{mms}$ and increase the nasolabial angle of $1.79^{\circ}$. In the treatment of Class I malocclusion with the extraction of the first four premolars, $1 \mathrm{~mm}$ of incisor retractions will change the position of the lips posteriorly as far as $0.067 \mathrm{mms}$ and increase the nasolabial angle of $2.87^{\circ}$. The anteroposterior upper incisor position change not only affects the position of the upper lip alone, but also influences the nasolabial angle. In this study, changes in lip position on S-Line were unaffected by the changes of the incisor positions before and after treatment.
\end{abstract}

Keywords-class I malocclusion, lip position, upper incisor position, pterygomaxillary vertical (PMV)

\section{INTRODUCTION}

Class I malocclusion treatments of the extraction of four premolar teeth are thought to cause "flattening face" due to anterior segment retractions, thus making this type of treatment less avoided. The treatment of Class I malocclusion with the extraction of the first four premolars will improve the profile when the analysis is performed correctly and appropriately $[1,2]$.

Facial esthetics and a well functional occlusion are the two essential objectives of any orthodontic treatment [3]. Cephalometric dentoskeletal analysis alone cannot predict the soft tissue outcome of treatment. In addition, the accurate initial position determination of the lips is essential for planning of proper treatment. Understanding the correlation between hard tissue and soft tissue before treatment is also important to predict the changes that may result from orthodontic intervention [4].

The vertical reference lines used to assess and evaluate hard and soft tissue changes position are $\mathrm{SN}-7^{\circ}$ and Pt-Vertical/Pterygomaxillary Vertical (PMV) [5]. Study about the influence of upper incisors position changes in the lip positions calculated using the pterygomaxillary vertical reference line (PMV) has not been performed in patients at Orthodontics Clinic Dental Health Hospital of Dentistry Faculty of Sumatera Utara University (RSGM FKG USU). The present study was aimed to investigate the position changes effect of upper incisors to upper lip and nasolabial angles in the treatment of Class I malocclusion non-extraction and by the extraction of the first four premolars.

\section{MATERIALS AND METHODS}

This cross-sectional research design explains the influence over variables through the hypothesis. The lateral cephalograms before and after treatment meeting the criteria were 40 subjects consisting of 20 subjects of Class I malocclusion treatment by non-extraction and 20 subjects by extraction of the first four premolars, to obtain a sample of 20 lateral cephalometric radiographs before and after treatment of Class I malocclusions nonextraction, 20 lateral cephalometric radiographs before and after treatment of Class I malocclusions with extraction of four first premolar.

The lateral cephalometric before and after treatment traced on tracing paper $(0.003$ inch, $8 \times 10$ inch, Ortho Organizer). The PMV (Pterygomaxillary Vertical) plane is made from the line drawn from the Se point to the $\mathrm{PM} / \mathrm{Pt}$ point based on the Enlow analysis, with the Pterygomaxillary (Pt/PM) point is the most inferior and most posterior point on the anterior outline of the pterygomaxillary fissure; Spheno-etmoidalis (Se) point is the point of intersection of the large sphenoid wing with the anterior base of the cranium fossa; the Labrale Superior point (LS) is the anterior most point of the upper lip or the point indicating the upper lip binding 
muco-cutaneous; and a point on the incisal edge of the upper incisors. The anteroposterior position of the upper incisors is measured by the horizontal distance between the PMV planes to the incisal point of the upper incisors at a line perpendicular to the PMV plane. The position of the upper lip is measured by the horizontal distance between the PMV planes to the LS point in the line perpendicular to the PMV plane. The Steiner S-line then obtained through a line drawn from the midpoint between the Subnasal (Sn) and Pronasal (Pn) or the inflection point of the columella to Pogonion soft tissue (Pog'), then measured the horizontal distance of the LS point to the S-Line in millimeters. The Nasolabial angle is formed by the intersection tangent of the nasal base line and the tangent line of the LS point, and measured in degrees (Figure 1 and 2).

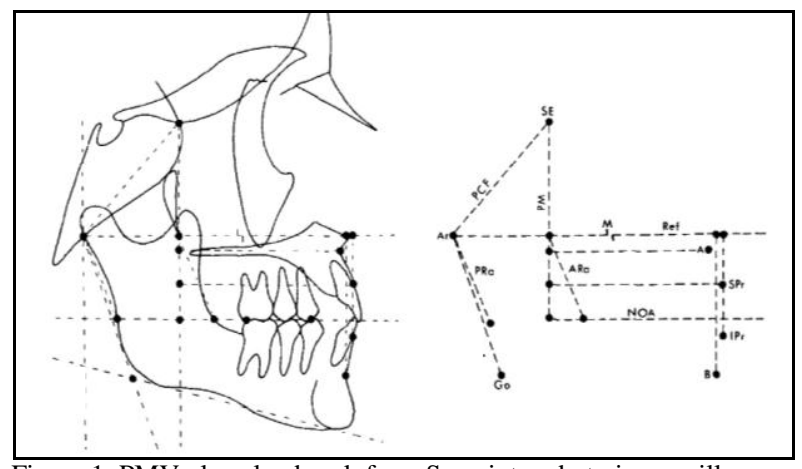

Figure 1. PMV plane landmark from Se point and pterigomaxillary from large sphenoid wing based on Enlow analysis.

Lateral cephalometric radiograph before and after treatment not superimposed because the occurrence of extrusion or intrusion of the anterior teeth during orthodontic intervention did not calculate. Data were analyzed descriptively, where the mean and standard deviation values were calculated. Paired sample t-test was used to determine the difference between measurement values before and after treatment of Class I malocclusions non-extraction and by extraction of the first four premolars. Comparisons of both Class I malocclusion treatments were demonstrated using an independent sample t-test. Evaluation of the effect or relationship between variables related to the level of significance to determine the effect of anteroposterior posterior upper incisor position changes in upper lip positions before and after orthodontic treatment used Pearson's correlation coefficient (r). Multiple stepwise regression analysis was then performed to obtain the ratio of upper lip and upper incisors. All data analysis done computerized by software method SPSS ver.1.4.

\section{RESULTS}

The sample measurements were done twice and then the results of the two measurements were tested using paired T-test. The test results showed no significant difference between first and second measurement ( $\mathrm{sig}=$ 0.998 ( $p>0.05)$ ). The test is conducted to avoid the occurrence of bias on the measurement results. Table I shows the correlation of anteroposterior position changes for each variable between before and after treatment of Class I malocclusion non-extraction and by extraction of the first four premolar. There is correlation between anteroposterior incisor position in PMV, upper lip position to PMV and nasolabial angle improvement in treatment of Class I malocclusion non-extraction and by extraction of the first four premolars. No correlation between lip-position changes into the $\mathrm{S}$-Line in treatment of Class I malocclusion non-extraction nor with the extraction of the first four premolars.

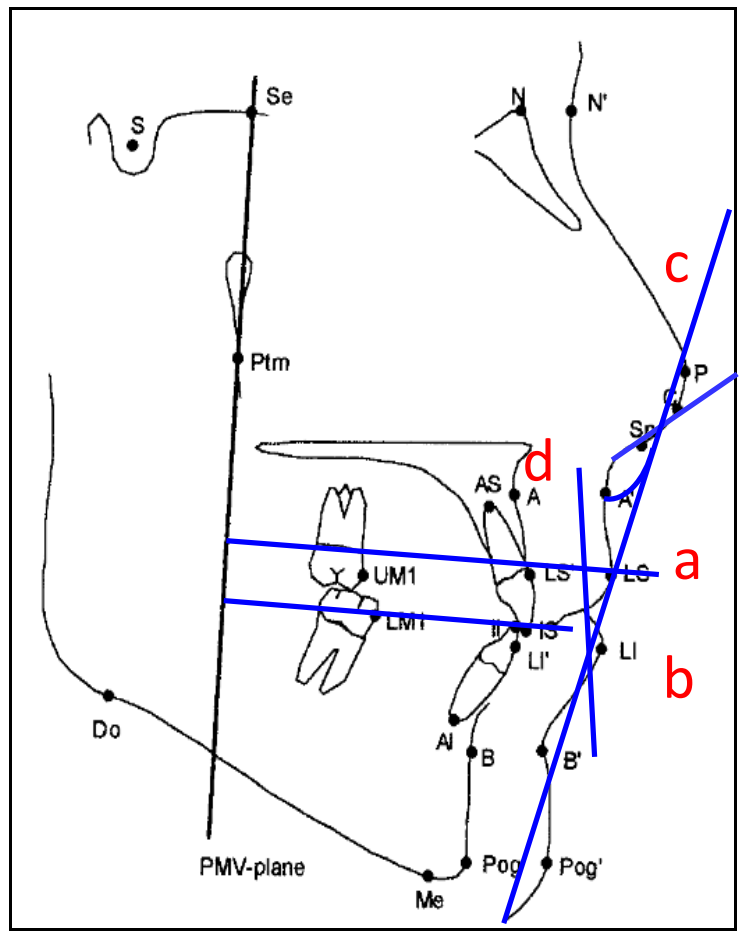

Figure 2. Measurement used in this study. a) PMV plane to LS; b) PMV plane to upper incisor; c) LS to S-Line; d) nasolabial angle[5].

Table II shows the significance of anteroposterior position changes for each variable between before and after treatment in Class I malocclusion non-extraction and by extraction of the first four premolars. There was no significant change in the anteroposterior position of the upper incisors to PMV, lip position to PMV, lip position to $\mathrm{S}$-line, and nasolabial angle before and after orthodontic treatment of Class I malocclusion nonextraction $(p>0.05)$. But, there was a significant change in the anteroposterior position of the upper incisor to the PMV, the lip position to the PMV, the lip positions to the S-Line, and the nasolabial angle before and after orthodontic treatment of Class I malocclusion with the extraction of the first four premolars $(p<0.05)$. 
TABLE I. CORRELATION OF ANTEROPOSTERIOR POSITION CHANGES OF EACH VARIABLE BEFORE AND AFTER TREATMENT IN CLASS I MALOCCLUSION NON-EXTRACTION AND BY EXTRACTION OF THE FIRST FOUR PREMOLARS

\begin{tabular}{|c|c|c|c|c|c|c|c|}
\hline \multicolumn{2}{|c|}{$\begin{array}{c}\text { Measurement } \\
\text { Variables }\end{array}$} & \multicolumn{3}{|c|}{ Non-extraction } & \multicolumn{3}{|c|}{$\begin{array}{c}\text { First Four Premolar } \\
\text { Extraction }\end{array}$} \\
\hline & & $\begin{array}{c}\text { Be- } \\
\text { fore } \\
\text { Treat- } \\
\text { ment }\end{array}$ & $\begin{array}{c}\text { After } \\
\text { Treat- } \\
\text { ment }\end{array}$ & $\begin{array}{c}\text { Corre- } \\
\text { lation } \\
(r)\end{array}$ & $\begin{array}{c}\text { Be- } \\
\text { fore } \\
\text { Treat- } \\
\text { ment }\end{array}$ & $\begin{array}{c}\text { After } \\
\text { Treat- } \\
\text { ment }\end{array}$ & $\begin{array}{c}\text { Corre- } \\
\text { lation } \\
(r)\end{array}$ \\
\hline $\begin{array}{c}\text { Nasolabial } \\
\text { angle }\end{array}$ & $\Sigma \mathrm{SD}$ & $\begin{array}{l}96.8 \\
10.1\end{array}$ & $\begin{array}{l}97.5 \\
11.9\end{array}$ & $62.6 \%$ & $\begin{array}{c}91.7 \\
7.2\end{array}$ & $\begin{array}{c}98.3 \\
3.7\end{array}$ & $64.3 \%$ \\
\hline PMV-U1 & $\Sigma \mathrm{SD}$ & $\begin{array}{c}67.7 \\
3.6 \\
\end{array}$ & $\begin{array}{l}67.8 \\
3.9 \\
\end{array}$ & $60.2 \%$ & $\begin{array}{l}66.0 \\
3.5 \\
\end{array}$ & $\begin{array}{c}63.3 \\
4.2 \\
\end{array}$ & $97.5 \%$ \\
\hline PMV-LS & $\Sigma \mathrm{SD}$ & $\begin{array}{c}77.3 \\
3.1 \\
\end{array}$ & $\begin{array}{c}77.8 \\
3.9 \\
\end{array}$ & $72.8 \%$ & $\begin{array}{c}75.5 \\
3.6 \\
\end{array}$ & $\begin{array}{c}72.2 \\
4.2 \\
\end{array}$ & $94.7 \%$ \\
\hline LS-S'line & $\Sigma \mathrm{SD}$ & $\begin{array}{l}0.5 \\
2.1 \\
\end{array}$ & $\begin{array}{l}0.8 \\
1.4 \\
\end{array}$ & $14.7 \%$ & $\begin{array}{l}2.1 \\
2.0\end{array}$ & $\begin{array}{l}0.4 \\
1.3 \\
\end{array}$ & $33.8 \%$ \\
\hline
\end{tabular}

TABLE II. SIGNIFICANCE OF ANTEROPOSTERIOR POSITION CHANGES OF EACH VARIABLE BEFORE AND AFTER TREATMENT IN CLASS I MALOCCLUSION NON EXTRACTION AND BY EXTRACTION OF THE FIRST FOUR PREMOLARS

\begin{tabular}{|c|c|c|c|c|c|c|}
\hline \multirow{2}{*}{ Variables } & \multicolumn{3}{|c|}{ Non-extraction } & \multicolumn{3}{c|}{ First Four Premolar } \\
& & \multicolumn{2}{|c|}{} & \multicolumn{3}{c|}{ Extraction } \\
\cline { 2 - 7 } & $\boldsymbol{\Sigma}$ & SD & p-value & $\boldsymbol{\Sigma}$ & SD & p-value \\
\hline Nasolabial Angle & 0.75 & 9.64 & 0.73 & 6.60 & 5.62 & $0.0001^{* *}$ \\
\hline PMV-U1 & 0.10 & 3.41 & 0.89 & -2.70 & 1.17 & $0.0001^{* *}$ \\
\hline PMV-LS & 0.45 & 2.70 & 0.46 & -3.25 & 1.37 & $0.0001^{* *}$ \\
\hline LS-S'line & 0.30 & 0.67 & 0.14 & -1.60 & 0.73 & $0.001^{*}$ \\
\hline
\end{tabular}

Table III shows the effect of anteroposterior posterior incisor position changes to upper lip positions and nasolabial angle improvement after treatment of Class I malocclusion non-extraction and by extraction of the first four premolars.

TABLE III. INFLUENCE OF ANTEROPOSTERIOR POSITION OF UPPER INCISORS TO UPPER LIP POSITION AND SLINE AFTER TREATMENT IN CLASS I MALOCCLUSION NON-EXTRACTION AND BY EXTRACTION OF THE FIRST FOUR PREMOLARS

\begin{tabular}{|c|c|c|c|c|}
\hline \multirow{3}{*}{ Variables } & \multicolumn{2}{|c|}{ Non-Extraction } & \multicolumn{2}{|c|}{$\begin{array}{c}\text { First Four Premolar } \\
\text { Extraction }\end{array}$} \\
\cline { 2 - 5 } & $\begin{array}{c}\text { Upper Incisor } \\
\text { Position Changes }\end{array}$ & \multicolumn{2}{c|}{$\begin{array}{c}\text { Upper Incisor } \\
\text { Position Changes }\end{array}$} \\
\cline { 2 - 5 } & $(\mathbf{r})$ & $(\mathbf{p})$ & $(\mathbf{r})$ & $(\mathbf{p})$ \\
\hline Nasolabial angle & -0.181 & $<0.001^{* *}$ & 0.120 & $<0.001^{* *}$ \\
\hline Upper lip & 0.905 & $<0.001^{* *}$ & 0.957 & $<0.001^{* *}$ \\
\hline S-Line & 0.273 & $>0.05$ & 0.339 & $>0.05$ \\
\hline
\end{tabular}

Statistically, there was a significant effect on the anteroposterior position of the upper incisors to the upper lip positions and nasolabial angles in the treatment of Class I malocclusion non-extraction ( $r \mathrm{U} 1$ $\mathrm{LS}=0.905)$ and by extraction of the first four premolars ( $r$ U1-LS $=0.957$ ). The effect of anteroposterior positions of upper incisors and upper lip positions to the $\mathrm{S}$-Line was no statistically significant in the treatment of Class I malocclusion non-extraction ( $r$ U1-LS-S'Line $=0.273)$ nor by extraction of the first four premolar $(r$ U1-LS-S'Line $=0.339$ ).

The results of Stepwise multiple regression analysis (Table IV) in Class I malocclusion non-extraction showed that for every $1 \mathrm{~mm}$ of upper incisor retractions will change the upper lip position calculated at the
Labrale superior point (LS) as far as $0.034 \mathrm{mms}$ posteriorly, and for every $1 \mathrm{~mm}$ upper incisor retractions will increase the nasolabial angle by $1.79^{\circ}$.

TABLE IV. RESULT OF STEPWISE REGRESSION ANALYSIS OF THE UPPER INCISOR EFFECT TO THE UPPER LIP AND NASOLABIAL ANGLE.

\begin{tabular}{|l|c|c|c|c|}
\hline & \multicolumn{2}{|c|}{$\begin{array}{c}\text { mm Upper Incisor } \\
\text { Retraction }\end{array}$} & \multicolumn{2}{|c|}{$\begin{array}{c}\mathbf{m} \text { Upper Incisor } \\
\text { Protraction }\end{array}$} \\
\hline & $\begin{array}{c}\text { Non- } \\
\text { Extraction }\end{array}$ & $\begin{array}{c}\text { With } \\
\text { Extraction } \\
\text { of 4P1 }\end{array}$ & $\begin{array}{c}\text { Non- } \\
\text { Extraction }\end{array}$ & $\begin{array}{c}\text { With } \\
\text { Extraction } \\
\text { of 4P1 }\end{array}$ \\
\hline Upper lip & $-0.034 \mathrm{~mm}$ & $-0.067 \mathrm{~mm}$ & $\begin{array}{c}+0.034 \\
\mathrm{~mm}\end{array}$ & $\begin{array}{c}+0.067 \\
\mathrm{~mm}\end{array}$ \\
\hline $\begin{array}{l}\text { Nasolabial } \\
\text { angle }\end{array}$ & $+1.79^{\circ}$ & $+2.87^{\circ}$ & $-1.79^{\circ}$ & $-2.87^{\circ}$ \\
\hline
\end{tabular}

The results of the Stepwise multiple regression analysis in Class I malocclusion with the extraction of the first four premolar indicate that for every $1 \mathrm{~mm}$ of the upper incisors retractions will change the upper lip position calculated at the Labrale superior point as far as $0.067 \mathrm{mms}$ posteriorly, and for every $1 \mathrm{~mm}$ upper incisor retractions will increase the nasolabial angle by $2.87^{\circ}$. This value is the opposite if the upper incisors are protracted.

\section{DISCUSSION}

The cephalometric analysis was performed by the lateral cephalometric radiograph tracing to obtain the value of anteroposterior distance changes in dentoskeletal and soft tissue relationships. Research by Khursid et al. in 2015 using the vertical reference line of $\mathrm{SN}-7^{\circ}$ and the study subjects confined to Class I malocclusion with bimaxillary protrusion, suggesting that Class I malocclusion treatment followed by incisor retraction due to the extraction of the first four premolars will result in a better change in soft tissue profile [5].

According to Khan and Fida study, significant changes were observed in the hard as well as soft tissue characteristics in the group of patients subjected to all 4 premolar extractions [6]. The effects of the two types of orthodontic treatment on the facial soft tissues were very similar, indicating that treatment, involving the extraction of premolars, does not have a detrimental effect on facial aesthetics provided the decision to extract is on sound basis and the mechanics are controlled [6]. Konstantonis study found that the nasiolabial angle became $5.34^{\circ}$ more obtuse in the extraction group, indicates that the non-extraction group showed significant upper lip retraction but lower lip protraction [7].

The ratio of the effect of upper incisors to upper lip on Khursid et al [5] study was 1:2.31. The ratio of Conley and Jernigan study was 1:2.68. The ratio on Waldman's study was 1:3.8. The subjects in this study were not specified by the patient's race specifically, but all subjects were Indonesians who largely belonged to the racial Australo-melanesian sub-race group of Deutro-Malay. In this study, the ratio of upper incisors to upper lip position in Class I malocclusion non- 
extraction was 1:0.02. The upper incisor position change ratio to the upper lip position in Class I malocclusion treatments with extraction of four premolars was 1:2.82.

Khursid study with subjects of Class I malocclusion with bimaxillary protrusion treated by extraction of first four premolars, found that every $1 \mathrm{~mm}$ of upper incisor retraction would retract the upper lip posteriorly as far as $0.049 \mathrm{~mm}$ and increase the nasolabial angle by $2.68^{\circ}$. This difference may be due to differences in the patient's race in the study subjects with different lip morphology [5]. The results of this study show that Class I malocclusion treatment with first four premolars extraction and followed by incisor retraction will result in better soft tissue alteration, thus improve the facial profile. Individual growth changes and unexpected aspects of orthodontic treatment response have a role in the occurrence of treatment outcomes variability in soft tissue profiles [3-8].

Initial examination in orthodontic treatment diagnosis accompanied by appropriate treatment plan and consideration of hard and soft tissue change based on individual differences should be done to obtain the most optimal care result for the patient. Avoiding treatment of first four premolars extraction in Class I malocclusions because of concerns that will cause detrimental effects on facial profiles such as flat face or dishing-in, should be no longer the primary reference in determining the treatment plan. Determination of nonextraction treatments or extraction of four premolars in Class I malocclusions should be performed comprehensively through analyzes that support orthodontic diagnostics, including the clinician attention on race and age of patients that are the contributing factor of determining the success of orthodontic treatment. As a conclusion, there is a significant effect on the upper incisor position to the lip position in Class I malocclusion non-extraction treatments and in Class I malocclusions by extraction of the first four premolars treatment, which affect the increase of nasolabial angle resulting in improved facial profiles.

\section{REFERENCES}

[1] C.B. Arcis, J.M. Montiel, J.M.A. Silla, "Orthodontic treatment need: an epidemiological approach. Orthodontics-basic aspects and clinical considerations," Intech-Croatia, vol. (1), pp. 1-28, March 2012.

[2] I.T.P. Silva, "Angle class I malocclusion treated with extraction of first permanent molars," Dental Press J. Orthod., vol. 15(4), pp. 133-143, 2010.

[3] M.K. Alam, S.A. Nourin, A. Yusof, B. Ahmad, Changes of lip morphology in relation to different skeletal index: in Malaysian Malay and Malaysian Chinese population," Int. J. Pharm. Bio. Sci., vol. 6(2), pp. (B)770-778, 2015.

[4] M.A. Shamlan, A.M. Aldrees, "Hard and soft tissue correlation in facial profiles: a canonical correlation study," Clin. Cosmetic Investig. Dentistry, vol. 7, pp.9-15, 2015.

[5] S.Z. Khursid, S.N. Qazi, N.M. Zargar, "Soft tissue changes associated with first premolar extractions in Khasmir female population,” J. Orofac. Res., vol. 5(1), pp. 18-21, 2015.

[6] M. Khan, M. Fida, "Soft tissue profile response in extraction versus non-extraction orthodontic treatment," J. Coll. Physic. Surg. Pakistan, vol. 20(7), pp. 454-459, 2010.
[7] D. Konstantonis, "The impact of extraction vs nonextraction treatment on soft tissue changes in class I borderline malocclusions," Angle Orthod., vol. 82, pp. 209-217, 2012.

[8] A.E. Erdinc, R.S. Nanda, T.C. Dandajena, "Profile changes of patient treated with and without premolar extractions," Am. J. Orthod. Dentofacial Orthop., vol. 132, pp. 24-31, 2007. 